\title{
Analysis of Salt Tolerance in Nine Leafy Vegetables Irrigated with Saline Drainage Water
}

\author{
Michael C. Shannon, Catherine M. Grieve, Scott M. Lesch, and John H. Draper \\ U.S. Deptartment of Agriculture, Agriculture Research Service, George E. Brown Jr., Salinity Laboratory, \\ 450 W. Big Springs Road, Riverside, CA 92507-4617
}

\begin{abstract}
ADDitional INDEX wORDs. salinity, salt stress, water reuse, irrigation water, drainage water
ABSTRAct. Saline agricultural drainage water may be used as a resource to grow high value horticultural crops and reduce the volume of drainage for eventual disposal. To explore reuse options the effects of salinity and timing of application were tested on selected leafy vegetables grown in 24 sand culture plots in Riverside, Calif. The leafy winter vegetables included 'Ruby Red Chard' Swiss chard [Beta vulgaris L. var. flavescens (Lam.) Lam.], 'Space' spinach (Spinacia oleracea L.), 'Vitamin Green' salad greens [Brassica rapa L. (Narinosa Group)], 'Red Giant' mustard greens [Brassica juncea L. (Czerniak)], pac choi [Brassica rapa L. (Chinensis Group)], 'Winterbor' kale [Brassica oleracea L. (Acephala Group)], tatsoi [Brassica rapa L. (Narinosa Group)], 'Salad King' curly endive (Cichorium endivia L.), and 'Red Preco No. 1' radicchio (Cichorium intybus $\mathrm{L}$.). All vegetables were planted at the same time and irrigated initially with tap water and nutrients. At 3 and 7 weeks after seeding (application times), six salinity treatments were initiated by adding salts to the irrigation water to represent the chemical compositions of drainage waters found typically in the San Joaquin Valley, Calif. The six salinity treatments had electrical conductivities of 3 (control), 7, 11, 15, 19, or $23 \mathrm{dS} \cdot \mathrm{m}^{-1}$. A randomized complete block design was used with ( 6 salinities $\times 2$ application times $\times 2$ replications). Within each plot a 1.5-m row of each of the nine vegetables was grown as split plots. Salinity reduced fresh weight (FW) yields of all species. Salt stress applied at 3 weeks after seeding reduced $F W s$ for seven of the nine vegetables compared to salination at 7 weeks. Analyses of salt tolerance curves, maximum yields, and the point of $50 \%$ yield reduction $\left(C_{50}\right)$ were conducted. Greens produced the highest biomass at $874 \mathrm{~g} /$ plant, but was the most affected by application time. Swiss chard and radicchio were not significantly affected by timing of salinity application, and Swiss chard was the most salt tolerant overall. Greens, kale, pac choi, and to a lesser extent, tatsoi, have potential as winter-grown, leafy vegetables in drainage water reuse systems.
\end{abstract}

As water quality and quantity becomes limited in many parts of the world, new options are sought to make more efficient use of agricultural drainage water. Since agriculture is the main use of our water supply, there is strong interest in increasing the efficiency of water use through reuse options. Reuse of saline water would preserve greater amounts of high quality water. Conditions in the San Joaquin Valley of California are a prime example of these problems. Because of potential environmental hazards, drainage water returns to rivers and estuaries on the Westside of the valley are being curtailed and restrictions have been placed on the creation of evaporation ponds (Johnston et al., 1997; Tanji et al., 1993).

It has been proposed that drainage water be reused as a primary method to reduce the volume of drainage that must be disposed (Rhoades, 1977; Rhoades et al., 1989). Drainage water reuse could reduce the area needed for evaporation ponds from $\approx 1$ ha/ 10 ha of irrigated land, to $\approx 1$ ha for each 200 ha of irrigated land (Oster, 1997). Cervinka (1994; Imhoff, 1990) has further advanced the concept of drainage water reuse through a succession of salt tolerant crops, trees, and eventually halophytes. Limitations to the adoption of drainage water reuse include economic concerns for the costs of developing the drainage and pumping infrastructure for such systems compared to the productivity costs for crops which can be grown. We propose an innovative elaboration of the drainage water reuse concept based on the production of high value horticultural crops that could serve niche

Received for publication 26 Mar. 1999. Accepted for publication 19 June 2000 Research reported herein was funded by the California Department of Water Resources (DWR B-59922), Project Manager, Fawzi Karajeh. We thank M. McGiffen, Univ. Calif., Riverside, J.D. McCreight, USDA-ARS, Salinas, Calif., D.A. Dierig, USDA-ARS, Phoenix, Ariz., and one anonymous reviewer for his helpful critiques and editorial comments. The cost of publishing this paper was defrayed in part by the payment of page charges. Under postal regulations, this paper therefore must be hereby marked advertisement solely to indicate this fact. markets. Potential crops include winter vegetables, flowers, herbs, medicinals, and other species that are tolerant to drainage water irrigation and would provide high economic return (Shannon and Grieve, 1999, 2000).

In this study, we used synthetic drainage water with ion composition similar to that found typically in the San Joaquin Valley to irrigate nine leafy winter vegetables. The purpose of the study was to determine potential yield and salt tolerance over a range of salinities and to determine if improved yields could be obtained if initial salination were delayed past the early plant establishment stage in which most plants are considered to be salt sensitive (Shannon et al., 1994).

\section{Materials and Methods}

Plant material and culture. Nine leafy vegetables from three families were chosen for this study. Two were Chenopodiaceae- 'Ruby Red' Swiss chard (Beta vulgaris var. flavescens), and 'Space' spinach (Spinacia oleracea); five were Brassicaceae-'Vitamin Green' salad greens (Brassica rapa), 'Red Giant' mustard greens (B. juncea), pac choi (B. rapa) (Johnny Seeds, Albion, Maine), 'Winterbor' kale (B. oleraceae), and tatsoi (B. rapa) (Johnny Seeds); and two were Asteraceae'Salad King' curly endive (Cichorium intybus) and 'Red Preco No. 1' radicchio (Chicorium intybus) (Johnny Seeds).

Experiments were conducted outdoors at Riverside, Calif., lat. 33E58'24', long. 117E58'12'). On 30 Jan. 1997, seeds were sown directly in sand culture tanks $(1.5 \times 3 \times 2 \mathrm{~m}$ deep $)$ filled with Lytle Creek sand with an average bulk density of $1.2 \mathrm{Mg} \cdot \mathrm{m}^{-3}$. At saturation, the sand had an average volumetric water content of $0.34 \mathrm{~m}^{3} \cdot \mathrm{m}^{-3}$. Each plot was irrigated with solutions prepared in an individual reservoir $(1.5 \mathrm{~m}$ diameter $\times 2.2 \mathrm{~m}$ deep $)$ having a volume of $\approx 4000 \mathrm{~L}$. The irrigation solutions were pumped from the reservoirs to the tanks and then returned to the reservoirs 
Table 1. Salinity treatments used in the experiment. ${ }^{\mathrm{z}}$

\begin{tabular}{|c|c|c|c|c|c|c|c|}
\hline & $\mathrm{EC}$ & $\mathrm{Ca}$ & $\mathrm{Mg}$ & $\mathrm{Na}$ & $\mathrm{SO}_{4}$ & $\mathrm{Cl}$ & $\mathrm{pH}$ \\
\hline Treatment & $\left(\mathrm{dS} \cdot \mathrm{m}^{-1}\right)$ & \multicolumn{6}{|c|}{$\left(\mathrm{meq} \cdot \mathrm{L}^{-1}\right)$} \\
\hline 1 & 3.0 & 7.0 & 4.9 & 21.5 & 21.8 & 7.0 & 7.8 \\
\hline 2 & 7.0 & 14.6 & 11.5 & 50.9 & 51.7 & 24.7 & 7.8 \\
\hline 3 & 11.0 & 20.3 & 19.6 & 87.0 & 84.0 & 42.2 & 7.7 \\
\hline 4 & 15.0 & 26.0 & 27.8 & 123.0 & 116.3 & 59.6 & 7.7 \\
\hline 5 & 19.0 & 26.9 & 37.9 & 168.0 & 150.4 & 81.3 & 7.6 \\
\hline 6 & 23.0 & 27.3 & 48.7 & 215.6 & 187.0 & 98.6 & 7.7 \\
\hline
\end{tabular}

${ }^{\mathrm{Z}}$ In addition, $6 \mathrm{meq} \cdot \mathrm{L}^{-1} \mathrm{KNO}_{3}$ and micronutrients (Hoagland and Arnon, 1950) were added to all solutions.

through a subsurface drainage system at the bottom of each sand tank. Initial irrigations consisted of basal nutrient solution made up in Riverside, Calif., tap water and nutrients $\left(\right.$ in $\left.\mathrm{mol} \cdot \mathrm{m}^{-3}\right): 3.5$ $\mathrm{Ca}^{2+}, 2.5 \mathrm{Mg}^{2+}, 21.5 \mathrm{Na}^{+}, 6.0 \mathrm{~K}^{+}, 10.9 \mathrm{SO}_{4}{ }^{2+}, 7.0 \mathrm{Cl}^{-}, 5.0 \mathrm{NO}_{3}{ }^{-}, 0.17$ $\mathrm{KH}_{2} \mathrm{PO}_{4}, 0.050 \mathrm{Fe}$ (as sodium ferric diethyleneamine pentaacetate), $0.023 \mathrm{H}_{3} \mathrm{BO}_{3}, 0.005 \mathrm{MnSO}_{4}, 0.0004 \mathrm{ZnSO}_{4}, 0.0002 \mathrm{CuSO}_{4}$, and $\left.0.0001 \mathrm{H}_{2} \mathrm{MoO}_{4}\right)$. The electrical conductivity of the solution was $\approx 3 \mathrm{dS} \cdot \mathrm{m}^{-1}$ (Table 1$)$.

The experimental design was a split plot with six salinity treatments and two salinization dates (early and late) as the main effects, and vegetable species as the subplot effects, with two replications. One $1.5 \mathrm{~m}$ row of each vegetable was planted as a subplot in each sand tank (main plot). Early salination was initiated 17 Feb. 1997, just after the first pair of true leaves were fully expanded on more than half the plants (272 degree-days after planting). Salts were added in four equal increments over a period of $4 \mathrm{~d}$. Salination was completed 338 degree-days after planting. Late salinization was imposed 3 weeks later (613 degree-days after planting) and completed in $4 \mathrm{~d}$ at 684 degreedays after planting. Since the first salinity level was used as the control, there was no time of treatment effect at this salinity level. Final electrical conductivities of the irrigation waters were 3, 7, $11,15,19$, or $23 \mathrm{dS} \cdot \mathrm{m}^{-1}$, and compositions of the saline solutions were formulated to represent a drainage water composition typical of the San Joaquin Valley. Based on the model of Suarez and Simunek (1997), modifications were made of the irrigation solutions as salinities increased to simulate concentration of the water representing conditions initializing drainage waters in sand tanks or hydroponics (Table 1). The simulations include dissolution and precipitation but omit cation exchange, as this is site specific.

At harvest, measurements were taken to determine the combined effects of sulfate-salinity and planting date on top fresh weight (FW) of the plants. Average FW yield was determined on a random sample of three plants of each species-plot combination. Plants were cut at the sand surface, rinsed, blotted dry, and weighed. Since maturity and harvest dates were different for each species, roots could not be harvested without damaging adjacent species.

Daytime air temperatures ranged from 13.5 to $34.7^{\circ} \mathrm{C}$ (mean $22.7^{\circ} \mathrm{C}$ ); and night temperatures were 3.7 to $16.1^{\circ} \mathrm{C}$ (mean 8.8 ${ }^{\circ} \mathrm{C}$ ) between the seeding and harvest dates (30 Jan. 1997 to $8 \mathrm{Apr}$. 1997). Daily relative humidity (RH) over the same period ranged from $3.4 \%$ to $95.4 \%$; mean day/night RH was $21.2 \% / 71.1 \%$.

Statistical MODELING AND ANALYSIS METHODOLOGY. Initial analysis of FW yield data was performed using a standard two factor main effect split-plot analysis of variance (ANOVA) model. A multivariate, multiple linear regression model was then used to further quantify the main effects (salinity and time to salination). This model was derived from an extension of the van Genuchten and Hoffman (1984) nonlinear salt tolerance equa- tion. Univariate versions of this regression model were used to describe individual yield response and to determine the statistical significance of overall salinity effects and time to salination for each vegetable. The fitted parameter estimates were used to estimate the salinity levels associated with the maximum yield, $50 \%$ yield reduction point $\left(\mathrm{C}_{50}\right)$, and to display graphically the final estimated salt tolerance curves against the actual data points.

The FW yield data were first analyzed using a two factor maineffect, split-plot model:

$\log \left(\mathrm{y}_{\mathrm{ijkm}}\right)=\mathrm{V}+\mathrm{B}_{\mathrm{i}}+\mathrm{S}_{\mathrm{j}}+\mathrm{T}_{\mathrm{k}}+\mathrm{ST}_{\mathrm{jk}}+\mathrm{B}(\mathrm{S} \times \mathrm{T})_{\mathrm{ijk}}+\mathrm{V}_{\mathrm{m}}+\mathrm{SV}_{\mathrm{jm}}+\mathrm{TV}_{\mathrm{km}}$ $+\mathrm{STV}_{\mathrm{jkm}}+\xi_{\mathrm{ijkm}}$

where $\mathrm{B}, \mathrm{S}, \mathrm{T}$, and $\mathrm{V}$ represent the blocking $(\mathrm{i}=1,2)$, salinity level $(\mathrm{j}=1,2, \ldots, 6)$, time of salination $(\mathrm{k}=1,2)$, and vegetable species $(\mathrm{m}=1,2, \ldots, 9)$, respectively, and $\xi_{\mathrm{ijkm}}$ represents the residual mean square error (RMSE). The analysis was performed on the log transformed FW data yield in order to stabilize variability because higher yields were typically much more variable than lower yields (Shannon, 1985). In this model, the main plot experimental error was estimated by the $\mathrm{B}(\mathrm{S} \times \mathrm{T})$ factor and used to test significance of salinity (S), time of salination (T), and ST interaction. Likewise, the RMSE was used to test significance of the subplot vegetable $(\mathrm{V})$, salinity $\times$ vegetable $(\mathrm{SV})$, time of salination $\times$ vegetable (TV), and STV interaction, respectively (Montgomery, 1984).

Although Eq. [1] represents a natural way to model split-plot experimental design data, in this application only the main plot factors are of primary interest and the salinity effect is a continuous, rather than a discrete factor. Moreover, it is desirable to model the FW yield response using a physiologically meaningful equation.

An alternative is to model FW yield reduction using the nonlinear salt tolerance equation described by van Genuchten and Hoffman (1984). Thus, with salinity as the only main factor, the following exponential yield response function could be used:

$y=\delta \exp \left(\alpha x-6 x^{2}\right)$

where y is FW yield, $\mathrm{x}$ is salinity, and $\delta, \alpha$, and 6 are empirical parameters which must be estimated from the salt tolerance data (van Genuchten and Hoffman, 1984). Other salt tolerance equations exist in the literature; however, Eq. [2] describes the relationship between yield and salinity as a smooth, continuous equation and can be easily converted into an ordinary regression equation using a log transformation. This second point facilitates stabilization of the FW yield variation (i.e., it changes a multiplicative error structure into an additive error structure). Under a log transformation, Eq. [2] becomes a simple quadratic regression equation:

$\begin{aligned} \log (\mathrm{y}) & =\log (\delta)+\alpha \mathrm{x}-6 \mathrm{x}^{2}+\xi \\ & =\beta_{0}+\beta_{1} \mathrm{x}+\beta_{2} \mathrm{x}^{2}+\xi\end{aligned}$ 
In Eq. [3], $\xi$ represents the residual error component, which is assumed to follow the standard normality and independence assumptions. Additionally, $\beta_{2}$ is assumed to be $\leq 0$.

In our split-plot vegetable experiment, Eq. [3] can be used to model the yield $\times$ salinity data of any of the vegetables. However, two additional factors must be accounted for: the blocking effect and the timing of salinity application. To incorporate these effects, Eq. [3] should be modified as follows:

$\log (y)=\gamma+\beta_{0}+\beta_{1} x+\beta_{2} x^{2}+\kappa_{0} t+\kappa_{1} x t+\kappa_{2} x^{2} t+\xi$

where $\gamma$ represents the blocking variable, $t$ represents a $0 / 1$ indicator variable which would be set equal to 1 during the late time of salination and 0 otherwise, and $\kappa_{0}, \kappa_{1}$, and $\kappa_{2}$ are used to describe the time of salination effect.

Equation [4] suggests that the change in the time of salination could result in an entirely new yield $\times$ salinity response function. However, the experimental design suggests that this should not necessarily occur. Specifically, since $3 \mathrm{dS} \cdot \mathrm{m}^{-1}$ irrigation water was used as a control salinity level, the yield reduction for a given vegetable species grown at this salinity level should not change due to the sand tank location (with the exception of the blocking effect). In other words, if we define $\mathrm{z}=\mathrm{x}-3$ and then estimate the following equation,

$\log (\mathrm{y})=\gamma+\beta_{0}+\beta_{1} \mathrm{z}+\beta_{2} \mathrm{z}^{2}+\kappa_{0} \mathrm{t}+\kappa_{1} \mathrm{zt}+\kappa_{2} \mathrm{z}^{2} \mathrm{t}+\xi$

we would expect to find that $\kappa_{0}=0$. (Note that $\kappa_{0}=0$ implies that the yield reduction at $3 \mathrm{dS} \cdot \mathrm{m}^{-1}$ is constant, which should be true since the control salinity level never increased throughout the experiment. Note also that defining $\mathrm{z}=\mathrm{x}-3$ causes the intercept in Eq. [5] to be redefined from 0 to 3.) If this is indeed true, then the $\kappa_{0} \mathrm{t}$ term can be dropped from Eq. [5], and hence the revised yield reduction model becomes

$\log (y)=\gamma+\beta_{0}+\beta_{1} z+\beta_{2} z^{2}+\kappa_{1} z t+\kappa_{2} z^{2} t+\xi$

In Eq. [6], two new tests can now be performed: $\kappa_{1}=\kappa_{2}=0$ and $\kappa_{2}=0$. If both tests are rejected (i.e., both tests are statistically significant) then it can be concluded that the time of salination effect is nonlinear. Likewise, if neither test can be rejected at a reasonable significance level, it can be concluded that there is no evidence of any time of salination effect. Finally, if the $\kappa_{1}=\kappa_{2}=$ 0 test appears statistically significant and the $\mathrm{k}_{2}=0$ test does not, then it can be concluded that the time of salination effect is predominantly linear. Additionally, this would suggest that Eq. [6] should be further reduced to:

$\log (\mathrm{y})=\gamma+\beta_{0}+\beta_{1} \mathrm{z}+\beta_{2} \mathrm{z}^{2}+\kappa_{1} \mathrm{zt}+\xi$

In Eq. [7], the final level of statistical significance associated with the time of salination can be determined by testing $\kappa_{1}=0$ and the overall salinity effect can be determined by testing $\beta_{1}=\beta_{2}=$ $\kappa_{1}=0$.

The hierarchical modeling approach outlined above provided a way to specify a set of physiologically meaningful equations (Eqs. [5] through [7]) in which the effects of the main plot treatment factors were examined and interpreted for each vegetable species. However, such a modeling approach should first be performed in a multivariate setting if more than one vegetable needs to be examined and the data arise from the same experiment. This is true because in a standard split-plot design, multiple species of vegetable yield data with the same main effect levels will come from the same sand tank (i.e., the same subplot experimental unit). Hence, it is reasonable to expect such data to be cross correlated. Therefore, multivariate versions of Eqs. [5],
[6], and [7] should be specified first, and multivariate tests of the corresponding parameter estimates should be performed before applying any univariate tests. Additionally, there will by necessity be replication in the yield response data when these data come from a split-plot design (in the sense that more than one yield value will be acquired at each specific combination of main effect factors). This allows construction of lack-of-fit tests from the residual sum of squares error estimate for each final, univariate salt-tolerance model (see Montgomery, 1984). These residual lack-of-fit tests can then be used to appraise the adequacy of the fitted salt tolerance equations. In other words, these tests can be used to determine if the fitted equations adequately describe all of the deterministic yield response variability.

It should be noted that the regression Eqs. [4] through [7] simply represent a special case of the general split-plot ANOVA model (Eq. [1]). Given that one is only interested in the main plot factors, Eq. [1] becomes

$\log \left(\mathrm{y}_{\mathrm{ijk}}\right)=\mathrm{v}+\mathrm{B}_{\mathrm{i}}+\mathrm{S}_{\mathrm{j}}+\mathrm{T}_{\mathrm{k}}+\mathrm{ST}_{\mathrm{jk}}+\mathrm{B}(\mathrm{S} \times \mathrm{T})_{\mathrm{ijk}}+\xi_{\mathrm{ijk}}$

where the $\mathrm{B}(\mathrm{S} \times \mathrm{T})_{\mathrm{ijk}}+\xi_{\mathrm{ijk}}$ component actually represents the residual error term for each vegetable type. In turn, if one assumes that the salinity reduction in log yield follows a continuous quadratic response function for each vegetable, then Eq. [8] can be further reduced to:

$\log \left(y_{i j k}\right)=v+B_{i}+\beta_{1} x_{j}+\beta_{2} x_{j}^{2}+T_{k}+\beta_{3} x_{j} T_{k}+\beta_{4} x_{j}^{2} T_{k}+B(S \times T)_{i j k}$ $+\xi_{\mathrm{ijk}}$

where $\mathrm{x}_{\mathrm{j}}$ represents the (continuous) salinity level and the remaining variables are defined as before. However, Eq. [9] is mathematically identical to Eq. [4]. Hence, the regression models can be derived directly from the split-plot ANOVA model.

\section{Results and Discussion}

Overall, yields of all nine vegetables were clearly reduced by increasing levels of salinity. Yields of two of the nine vegetables, mustard greens, and salad greens, were also strongly reduced by early salinity application. Plant yields were reduced by both the degree of salinity concentration and application time. Variation also occurred due to species, however, species differences were not specifically correlated to taxonomic family relationships.

Preliminary analysis of the data confirmed that the highest yields were associated with the lowest salinity levels and late salinity treatment, and that higher FW yields were much more variable than lower yields. Shannon (1985) noted previously that higher yields under control or low salinity conditions are typically more variable than yields under relatively higher salinities. Therefore, all of the average FW yield data were log transformed before performing the ANOVA and regression model analysis. The split-plot model described the log yield data quite well; the model $R^{2}$ value was 0.966 and the calculated CV was $6.2 \%$ (Table 2). Results of the main effect $\mathrm{F}$ test indicated that both the salinity level and time of salination effects were highly significant. Additionally, the salinity $\times$ time of salination interaction was also significant, suggesting that the yield reduction due to time of salinity application changed across different salinities. Not surprisingly, the subplot vegetable species effect was also highly significant. The salinity $\times$ variety and time of salination $\times$ variety interactions were statistically significant as well, suggesting that the effects of salt tolerance and time of salination vary from one vegetable to another.

Given the high significance of the treatment effects, the log 
Table 2. Split-plot ANOVA model and F test results for log fresh weight yield data. ${ }^{\mathrm{z}}$

\begin{tabular}{|c|c|c|c|c|c|}
\hline Model $R^{2}$ & 0.9656 & & & & \\
\hline Model CV & $6.19 \%$ & & & & \\
\hline \multirow[t]{3}{*}{ Residual error estimate } & 0.0916 & & & & \\
\hline & \multicolumn{5}{|c|}{ Mean square estimates and $\mathrm{F}$ test results } \\
\hline & Source ${ }^{y}$ & df & MS & F test & $P>\mathrm{F}$ \\
\hline \multirow[t]{4}{*}{ Main plot effects } & $\mathrm{B}$ & 1 & 2.286 & & \\
\hline & $\mathrm{S}$ & 5 & 20.942 & 83.80 & 0.0001 \\
\hline & $\mathrm{T}$ & 1 & 3.525 & 14.10 & 0.0032 \\
\hline & ST & 5 & 1.249 & 5.00 & 0.0124 \\
\hline Main plot error & $\mathrm{B}(\mathrm{S} \times \mathrm{T})$ & 11 & 0.250 & & \\
\hline \multirow[t]{4}{*}{ Subplot effects } & $\mathrm{V}$ & 8 & 11.196 & 122.18 & 0.0001 \\
\hline & $\mathrm{S} \times \mathrm{V}$ & 40 & 0.231 & 2.52 & 0.0001 \\
\hline & $\mathrm{T} \times \mathrm{V}$ & 8 & 0.269 & 2.93 & 0.0059 \\
\hline & $\mathrm{S} \times \mathrm{T} \times \mathrm{V}$ & 40 & 0.107 & 1.17 & 0.2698 \\
\hline
\end{tabular}

${ }^{\mathrm{z}}$ Only 210 observations of the 216 possible observations were available for analysis because three, one and two plants died in the pac choi, tatsoi, and salad greens data sets, respectively. Thus, the average yields of these treatment combinations could not be calculated.

${ }^{\mathrm{y}} \mathrm{B}=$ block, $\mathrm{S}=$ salinity, $\mathrm{T}=$ time of salination, and $\mathrm{V}=$ vegetable.

Table 3. Multivariate multiple linear regression parameter test results, using Wilk's Lambda test statistic. Results based on simultaneous modeling of log fresh weight yield data of all nine vegetables.

\begin{tabular}{lccc}
\hline \hline Equation & Parameter test & $\mathrm{F} \mathrm{test}^{\mathrm{Z}}$ & $P>\mathrm{F}$ \\
\hline 5 & $\kappa_{0}=0$ & 1.50 & 0.3415 \\
6 & $\kappa_{1}=\kappa_{2}=0$ & 2.25 & 0.0774 \\
6 & $\kappa_{2}=0$ & 1.10 & 0.4733 \\
7 & $\kappa_{1}=0$ & 4.87 & 0.0244 \\
7 & $\beta_{1}=\beta_{2}=\kappa_{1}=0$ & 3.87 & 0.0011 \\
\hline
\end{tabular}

${ }^{\mathrm{z}} \mathrm{F}$ test is approximate.

Table 4. Univariate multiple linear regression modeling results using Eq. [7]. Model summary statistics presented are $R^{2}, \mathrm{CV}$, and residual error estimate.

\begin{tabular}{lccc}
\hline \hline Vegetable & $R^{2}$ & CV $(\%)$ & $\begin{array}{c}\text { Residual } \\
\text { error }\end{array}$ \\
\hline Mustard greens & 0.857 & 6.6 & 0.1265 \\
Pac choi & 0.805 & 10.1 & 0.2783 \\
Salad greens & 0.898 & 5.7 & 0.1122 \\
Swiss chard & 0.798 & 4.4 & 0.0574 \\
Kale & 0.743 & 8.9 & 0.1906 \\
Tatsoi & 0.847 & 6.7 & 0.1186 \\
Spinach & 0.814 & 7.4 & 0.1022 \\
Endive & 0.908 & 7.4 & 0.0964 \\
Radicchio & 0.833 & 10.9 & 0.1511 \\
\hline
\end{tabular}

transformed FW yield data from Eq. [3] were fit to hierarchical, multivariate regression models in order to account for the effects of time of salinity application and blocking (Table 3). Equation [5] was first fit to the $\log$ yield data and a test of $\kappa_{0}=0$ was performed across all nine vegetables. The resulting F test score of 1.50 was not found to be statistically significant using the Wilk's Lambda test statistic $(\alpha=0.3415)$. Equation [6] was fit to the same data, and two additional parameter tests were performed. The multivariate test of $\mathrm{k}_{2}=0$ was not statistically significant $(\alpha$ $=0.4733$ ); however, the joint multivariate test of $\kappa_{1}=\kappa_{2}=0$ was marginally significant $(\alpha=0.0774)$. These results suggested that the quadratic time of salination parameter should be removed from the model. Hence, Eq. [7] was next fit to the log yield data, and the multivariate test of $\kappa_{1}=0$ was found to be statistically significant at $\alpha=0.05$ level $(\alpha=0.0244)$. An approximate $F$ test associated with the joint parameter hypothesis of $\beta_{1}=\beta_{2}=\kappa_{1}=0$ was also performed and found to be statistically significant $(\mathrm{F}=$ 3.87, $\alpha=0.0011$ ).

It was concluded that Eq. [7] provided the most reasonable description of the log FW yield data; i.e., the time of salination effect upon the log yield data appeared to manifest itself in a predominantly linear manner on the log scale. Additionally, the $\mathrm{F}$ test results suggested that yields of one or more of the nine vegetables were affected by both the increasing salinity levels and the time of salinity application. The corresponding univariate model statistics, parameter test statistics, and lack-of-fit test statistics were calculated for each vegetable. The individual model $R^{2}$ values ranged from 0.8 to 0.9 , and the cv estimates fell between $4.4 \%$ to $10.9 \%$ (Table 4 ). The overall salinity effect on the log yield data was highly significant $(\alpha=0.0001$ for all nine vegetables), and the time of salination effect was statistically significant in seven out of the nine (Table 5). The lack-of-fit test statistics suggests that moderately significant lack-of-fit (i.e., model bias) may have occurred in three of the vegetables (Table $6)$.

The 6 quadratic parameter in the van Genuchten and Hoffman (1984) salt tolerance equation is supposed to be constrained to be $\leq 0$, which implies that $\beta_{2}$ must be $\leq 0$. However, it was not necessary to impose this restriction when estimating Eq. [7] using any of the nine vegetable data sets, because $b_{2}$ estimates were found to be $<0$ without constraints.

The final predicted salt tolerance curves were calculated using the parameter estimates from Eq. [7] for each vegetable species by 1) averaging out the block effect, 2) predicting the log FW yield response between a salinity range of 3.0 to $23.0 \mathrm{dS} \cdot \mathrm{m}^{-1}$ for both the early and late times to salination, and 3) calculating the back transformed yield level as $\exp (y)$, where y represented the regression model prediction. Note that these back transformed salt tolerance curves predict the geometric mean FW yield for specific salinity levels and time of salination.

Increasing salinity strongly reduced yields of Swiss chard and mustard greens, and moderately reduced yield of spinach (Fig. 1). In Swiss chard the effects of applying salt at 3 weeks after seeding was not more detrimental than applying salt 7 weeks after seeding (Fig. 1D); whereas earlier application of salinity caused significantly greater yield reductions in mustard greens and spinach 
Table 5. Univariate multiple linear regression parameter $\mathrm{F}$ test results using Eq. [7].

\begin{tabular}{lrrrr}
\hline \hline & F test & \multicolumn{1}{c}{$P>\mathrm{F}$} & $\mathrm{F}$ test & $P>\mathrm{F}$ \\
\cline { 2 - 5 } & \multicolumn{4}{c}{ Parameter test } \\
Vegetable & $\kappa_{1}=0$ & & $\beta_{1}=\beta_{2}=\kappa_{1}=0$ \\
\hline Mustard greens & 20.56 & 0.0002 & 37.27 & 0.0001 \\
Pac choi & 5.36 & 0.0342 & 21.03 & 0.0001 \\
Salad greens & 27.39 & 0.0001 & 49.72 & 0.0001 \\
Swiss chard & 0.05 & 0.8370 & 25.04 & 0.0001 \\
Kale & 5.56 & 0.0293 & 17.83 & 0.0001 \\
Tatsoi & 5.10 & 0.0366 & 31.56 & 0.0001 \\
Spinach & 5.08 & 0.0362 & 26.69 & 0.0001 \\
Endive & 6.68 & 0.0182 & 61.45 & 0.0001 \\
Radicchio & 0.36 & 0.5580 & 31.29 & 0.0001 \\
\hline
\end{tabular}

Table 6. Lack-of-fit regression model $\mathrm{F}$ test results pertaining to Eq. [7].

\begin{tabular}{lcc}
\hline \hline Vegetable & F test & $P>$ F \\
\hline Mustard greens & 0.98 & 0.4978 \\
Pac choi & 3.12 & 0.0639 \\
Salad greens & 0.77 & 0.6395 \\
Swiss Chard & 1.34 & 0.3196 \\
Kale & 0.69 & 0.6963 \\
Tatsoi & 1.75 & 0.2003 \\
Spinach & 0.57 & 0.7794 \\
Endive & 2.46 & 0.0839 \\
Radicchio & 2.80 & 0.0583 \\
\hline
\end{tabular}

(Fig. 1A and G). The maximum yield of Swiss chard was calculated to be $435 \mathrm{~g}$ at $3.0 \mathrm{dS} \cdot \mathrm{m}^{-1}$ and the point of $50 \%$ yield reduction $\left(\mathrm{C}_{50}\right)$ was found to occur at $\approx 14.5 \mathrm{dS} \cdot \mathrm{m}^{-1}$. Thus, Swiss chard was one of the most tolerant vegetables and could be subjected to salinity during early vegetative growth.

Early salination had a detrimental effect on salt tolerance of spinach and the $\mathrm{C}_{50}$ yield reduction point was reduced from 13.4 $\mathrm{dS} \cdot \mathrm{m}^{-1}$ at late salination, to $10.7 \mathrm{dS} \cdot \mathrm{m}^{-1}$ at early salination. A maximum yield of $160 \mathrm{~g} /$ plant was calculated for both salt tolerance curves. From these results it can be concluded that with late salination the salt tolerance of spinach is nearly as high as Swiss chard, but spinach yield would be more greatly reduced if salinity were applied at an earlier stage of growth. Average maximum yield of mustard greens was calculated to be $511 \mathrm{~g} / \mathrm{plant}$ at $3.0 \mathrm{dS} \cdot \mathrm{m}^{-1}$, and the $\mathrm{C}_{50}$ yield reduction point in the late time of salination curve occurred at $\approx 15.2 \mathrm{dS} \cdot \mathrm{m}^{-1}$. Earlier salination effectively reduced the $C_{50}$ point to $\approx 10.0$ $\mathrm{dS} \cdot \mathrm{m}^{-1}$. With late salination, the relative salt tolerance of mustard greens was comparable to Swiss chard and spinach, but early salination significantly reduced the tolerance of mustard greens.

Increasing salinity strongly decreased yields of pac choi, kale, and tatsoi (Fig. 1B, $\mathrm{E}$, and F). Earlier application of salinity had a moderate effect for all three vegetables compared to later salinization (Table 5). Kale had the poorest correlation with the model $\left(R^{2}=0.743\right)$ among all nine vegetables (Table 4), whereas, the residual error estimate (0.2783) for pac choi was the largest among all vegetables.

The $\mathrm{C}_{50}$ yield reduction point in the late time of salination curve for kale occurred at $\approx 15.0 \mathrm{dS} \cdot \mathrm{m}^{-1}$, while the $\mathrm{C}_{50}$ point in the early curve occurred at $11.1 \mathrm{dS} \cdot \mathrm{m}^{-1}$. The average maximum yield for kale was calculated to be $288 \mathrm{~g} / \mathrm{plant}$ at $3.0 \mathrm{dS} \cdot \mathrm{m}^{-1}$. The late and early maximum yields for pac choi were $426 \mathrm{~g} / \mathrm{plant}$ at 4.1 $\mathrm{dS} \cdot \mathrm{m}^{-1}$ and $423 \mathrm{~g} / \mathrm{plant}$ at $3.0 \mathrm{dS} \cdot \mathrm{m}^{-1}$, respectively. The late and early $\mathrm{C}_{50}$ estimates were calculated to be 15.3 and $11.6 \mathrm{dS} \cdot \mathrm{m}^{-1}$, respectively. The apparent model bias suggests that both the maximum yield and $\mathrm{C}_{50}$ estimates are probably unreliable. The point of the $\mathrm{C}_{50}$ yield reductions for tatsoi were calculated to occur at $17.0 \mathrm{dS} \cdot \mathrm{m}^{-1}$ in the case of late salination and at $14.2 \mathrm{dS} \cdot \mathrm{m}^{-1}$ in the case of early salination. The average maximum late and early yields for tatsoi were calculated to be $302 \mathrm{~g} /$ plant at $3.0 \mathrm{dS} \cdot \mathrm{m}^{-1}$ and $294 \mathrm{~g} / \mathrm{plant}$ at $5.4 \mathrm{dS} \cdot \mathrm{m}^{-1}$, respectively.

Increasing salinity also strongly reduced yields of endive, salad greens, and radicchio (Fig 1H, C, and I). Early time of salinity application strongly reduced yields of salad greens and endive as compared with delayed salinity application, but not radicchio (Table 5). The $\mathrm{C}_{50}$ point for the late and early time of salination curves for salad greens occurred at $\approx 14.4 \mathrm{dS} \cdot \mathrm{m}^{-1}$ and $9.4 \mathrm{dS} \cdot \mathrm{m}^{-1}$, respectively. This indicates a rather significant impact on relative salt tolerance due to early salination. The average maximum yield for salad greens was calculated to be $874 \mathrm{~g} / \mathrm{plant}$ at $3.0 \mathrm{dS} \cdot \mathrm{m}^{-1}$.

Based on the assumption of equivalent intercepts across the two salination times, the average maximum yield for endive was calculated to be $159 \mathrm{~g} /$ plant. The $\mathrm{C}_{50}$ yield reduction point in the late time of salination curve occurred at $\approx 14.6 \mathrm{dS} \cdot \mathrm{m}^{-1}$, while the $\mathrm{C}_{50}$ point in the early curve occurred at $\approx 12.3 \mathrm{dS} \cdot \mathrm{m}^{-1}$. Endive had different average yields in the two replicate sets at the $3.0 \mathrm{dS} \cdot \mathrm{m}^{-1}$ control level. This implies that the two salt tolerance curves might have different intercepts. However, the multivariate intercept test

Fig. 1. Salt tolerance of (A) mustard greens, $(\mathbf{B})$ pac choi, $(\mathbf{C})$ salad greens, (D) Swiss chard, (E) kale, (F) tatsoi, $(\mathbf{G})$ spinach, $(\mathbf{H})$ endive, and (I) raddicchio grown in sand cultures and irrigated with drainage water from 3 (early, open circle) and 7 (late, open square) weeks after seeding.

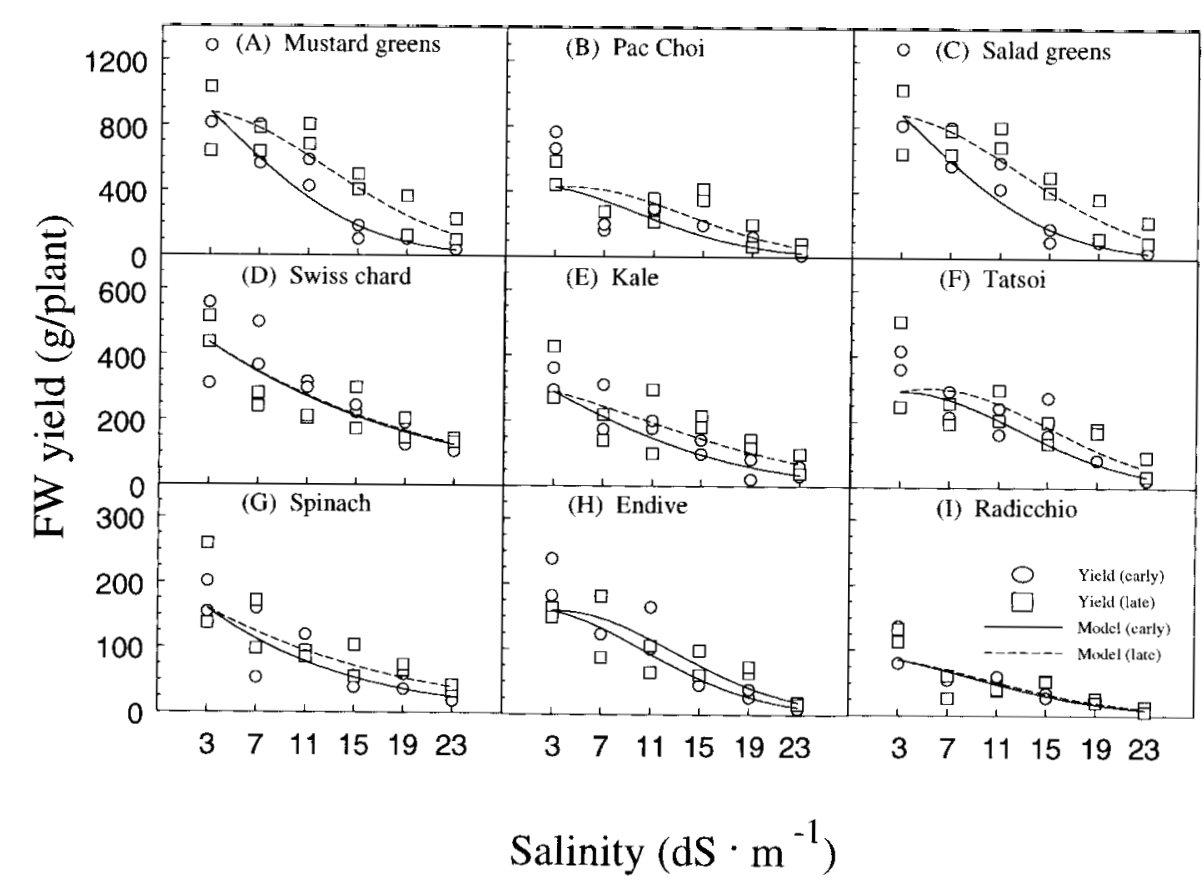


Table 7. Predicted values for maximum yields, and the salinity levels that would result in a $50 \%$ yield reduction $\left(\mathrm{C}_{50}\right)$ for nine leafy vegetables in which salinization was initiated at two different times (early and late).

\begin{tabular}{|c|c|c|c|c|}
\hline \multirow[b]{2}{*}{ Family } & \multirow[b]{2}{*}{ Vegetable } & \multirow{2}{*}{$\begin{array}{l}Y_{\max } \\
\text { fresh wt } \\
\text { g/plant }\end{array}$} & $\begin{array}{c}\mathrm{C}_{50} \\
\text { early }\end{array}$ & $\begin{array}{l}\mathrm{C}_{50} \\
\text { late }\end{array}$ \\
\hline & & & \multicolumn{2}{|c|}{$\mathrm{dS} \cdot \mathrm{m}^{-1}$} \\
\hline \multirow[t]{2}{*}{ Chenopodiaceae } & Spinach & 160 & 10.7 & 13.4 \\
\hline & Swiss chard & 435 & 14.5 & 14.5 \\
\hline \multirow[t]{5}{*}{ Brassicaceae } & Salad greens & 874 & 9.4 & 14.4 \\
\hline & Mustard greens & 511 & 10.2 & 15.2 \\
\hline & Kale & 288 & 11.1 & 15.0 \\
\hline & Pac choi & $425^{z}$ & 11.6 & 15.3 \\
\hline & Tatsoi & $298^{z}$ & 14.2 & 17.0 \\
\hline \multirow[t]{2}{*}{ Asteraceae } & Endive & 159 & 12.3 & 14.6 \\
\hline & Radicchio & 86 & $12.5^{\mathrm{y}}$ & $12.5^{\mathrm{y}}$ \\
\hline
\end{tabular}

${ }^{\mathrm{z} N u m e r i c a l}$ average of early and late salination.

yMay be over estimated due to model bias.

clearly rejected such a hypothesis (Table 3), which suggests that the marginal lack-of-fit evidence in the endive yield data is probably due to random variation. The maximum yield for both salt tolerance curves was calculated to be at $\approx 3.0 \mathrm{dS} \cdot \mathrm{m}^{-1}$.

Increasing salinity strongly decreased radicchio yield (Fig. 3C), but there was no significant effect of salination time (Table 5). Based on the estimated parameters, the maximum yield was calculated to be $86 \mathrm{~g} /$ plant at $3.0 \mathrm{dS} \cdot \mathrm{m}^{-1}$ and the $\mathrm{C}_{50}$ yield reduction was found to occur at $\approx 12.5 \mathrm{dS} \cdot \mathrm{m}^{-1}$. However, the $\mathrm{C}_{50}$ estimate may be unreliable due to the apparent model bias discussed previously. Average yield of marketable radicchio can be expected to be much higher than reported in these studies. Maximum yields were undoubtedly influenced by early harvest dates.

These observations on salt tolerance are confirmed by the $\mathrm{F}$ test results (Table 5). The nonsignificant lack-of-fit F test suggests that Eq. [7] described fully the variation in the yield data of Swiss chard, salad greens, spinach, kale, and mustard greens; however the lack-of-fit $F$ test of pac choi, tatsoi, and radicchio were significantly below the $\alpha=0.1$ level (Table 6 ). The observed data suggest that there was a sudden, discontinuous reduction in yields between 3.0 and $7.0 \mathrm{dS} \cdot \mathrm{m}^{-1}$, which Eq. [7] cannot describe adequately.

In conclusion, it is possible that drainage water or low quality, saline water from other sources can be reused to irrigate some salt tolerant vegetable crops after germination and seedling establishment under nonsaline conditions. However, it is critical to know what impact early applications of saline water will have on yields. Overall, yields of all nine vegetables were clearly reduced by increasing levels of salinity, and yields of two of the nine vegetables, mustard greens and salad greens, were also strongly reduced by early time of salination. But it was also found that saline drainage waters may be applied earlier to crops like Swiss chard and possibly radicchio without any more reduction in yield than would normally be expected. Yields of the other five vegetables (spinach, kale, pac choi, tatsoi, and endive) were moderately reduced by early time of salination.

The statistical significance of salinity and time of salination effects across these vegetables was indicated by the main factor split-plot ANOVA test results, and confirmed by the hierarchical salt tolerance modeling approach. Additionally, the multivariate Wilk's Lambda tests associated with the hierarchical modeling approach suggested that the time of salination effect caused the log yield data to decrease in a linear manner. This implies that the early salination time caused the $\mathrm{FW}$ yields to decrease in a proportional manner.

Drainage waters could conceivably be used for the irrigation of winter vegetable crops if salinities are not excessive (i.e., EC of the soil water from 10 to $15 \mathrm{dS} \cdot \mathrm{m}^{-1}$ ). Some vegetables examined in these studies have moderate salt tolerance based on relative growth rates and $\mathrm{C}_{50}$ values (Table 7 ). Only spinach and radicchio had $\mathrm{C}_{50}$ values $<14 \mathrm{dS} \cdot \mathrm{m}^{-1}$. Scant information exists on the salt tolerance of radicchio, but the accepted values for salinity threshold and slope reductions of spinach due to salinity measured in a saturated soil extract $\left(\mathrm{EC}_{\mathrm{e}}\right)$ are $2.0 \mathrm{dS} \cdot \mathrm{m}^{-1}$ and $7.6 \%$, respectively (Maas and Hoffman, 1977). Based on these values, the calculated $\mathrm{EC}_{\mathrm{e}}$ for $\mathrm{C}_{50}$ in spinach would be $\approx 8.6 \mathrm{dS} \cdot \mathrm{m}^{-1}$ as compared to the $\mathrm{EC}_{\mathrm{i}}$ value of $10.7 \mathrm{dS} \cdot \mathrm{m}^{-1}$ derived from early salination in this study (Table 7). This is generally in line with expectations since $\mathrm{EC}_{\mathrm{e}}$ values would be expected to be less than the average soil water salinity.

Model predictions of yields at $15 \mathrm{dS} \cdot \mathrm{m}^{-1}$ using late times of salination were 409, 260, 219 and $214 \mathrm{~g} /$ plant for salad greens, mustard greens, pac choi, and Swiss chard, respectively. Even when salinity is applied at an earlier stage of growth, the model predicts that yields of salad greens and Swiss chard at $15 \mathrm{dS} \cdot \mathrm{m}^{-1}$ would be 181 and $210 \mathrm{~g} / \mathrm{plant}$, respectively. Thus, these vegetables have a reasonable capacity for high growth under saline conditions. Crop yields under field conditions could be improved further by allowing longer periods until harvest, by the selection of species or cultivars that have faster growth rates during periods of natural winter rainfall or by using closer row spacings to compensate for expected decreases in individual plant size. Smaller plant size may not be detrimental to market acceptability, especially for the chopped leafy vegetable market. Additionally, local conditions may improve relative salt tolerance. Hoffman (1973) and Hoffman and Rawlins (1971) found that low temperatures and high humidity improved yield of green beans (Phaseolus vulgaris L.) and onions (Allium cepa L.) grown under salinity stress. The San Joaquin Valley is favored with cooler climate and more cloudy days during the winter as compared to Riverside, Calif.

Whether or not leafy vegetables have a niche in drainage water reuse schemes is a question that is still open to considerable investigation and research. In this study we have not considered potential effects of toxic ions that occur in some drainage waters or the long-term detrimental effects that drainage water can have on soil structure. The potential human health and nutrition effects 
of saline drainage water on leaf mineral composition is addressed in another report (unpublished). However, we have demonstrated that some vegetables may be better candidates than others in drainage water reuse systems due to more rapid growth rates and/ or their tolerance to saline irrigation during earlier growth stages. Because of the need to find economic ways to concentrate drainage water through reuse, the concept of using drainage water to grow a high value crop has considerable appeal.

\section{Literature Cited}

Cervinka, V. 1994. Agroforestry farming system for the management of selenium and salt on irrigated farmland, p. 237-250. In: W. Frankenberger, Jr., and S. Benson (eds.). Selenium in the environment. Marcel Dekker, New York.

Hoagland, D.T. and D.I. Arnon. 1950. The water culture method for growing plants without soil. Univ. Calif. (Berkeley) Agr. Expt. Sta. Circ. 347. (revised).

Hoffman, G.J. 1973. Humidity effects on yield and water relations of nine crops. Trans. Amer. Soc. Agr. Eng. 16:164-167.

Hoffman, G.J. and S.L. Rawlins. 1971. Growth and water potential of root crops as influenced by salinity and relative humidity. Agron. J. 63:877-880.

Imhoff, E.A. 1990. San Joaquin Valley Drainage Program. A management plan for agricultural subsurface drainage and related problems on the westside San Joaquin Valley: Final report of the San Joaquin Valley Drainage Program, Sept. 1990. Dept. Water Resources, San Joaquin Valley, Calif.

Johnston, W.R., K.K. Tanji, and R.T. Burns. 1997. Drainage water disposal, p. 51-62. In: C.A. Madramootoo, W.R. Johnston, and L.S. Willardson (eds.). Management of agricultural drainage water quality. Water Rpt. 13. Intl. Comm. Irr. Drain. (ICID), Food Agr. Org.-United Nations, Rome.

Maas, E.V. and G.J. Hoffman. 1977. Crop salt tolerance-Current assessment. J. Irr. Drain., Div. Amer. Soc. Civil Eng. 103(IR2):115134.

Montgomery, D.C. 1984. Design and analysis of experiments. 2nd ed. Wiley, New York.

Oster, J.D. 1997. Impact of alternative crops on salt disposal strategies. Proc. 1997 Calif. Plant and Soil Conf., June 1997. p. 38-42.

Rhoades, J.D. 1977. Potential for using saline agricultural drainage waters for irrigation. Proc. Water Mgt. for Irrig. and Drainage, Amer. Soc. Civil Eng./Reno, Nev., July 1977. p. 85-116.

Rhoades, J.D., F.T. Bingham, J. Letey, G.J. Hoffman, A.R. Dedrick, P.J. Pinter, and J.A. Replogle. 1989. Use of saline drainage water for irrigation: Imperial Valley study. Agr. Water Mgt. 16:25-36.

Shannon, M.C. 1985. Principles and strategies in breeding for higher salt tolerance. Plant and Soil. 89: 227-241.

Shannon, M.C. and C.M. Grieve. 1999. Tolerance of vegetable crops to salinity. Sci. Hort. 78:5-38.

Shannon, M.C. and C.M. Grieve. 2000. Options for using poor-quality water for vegetable crops. HortScience (in press).

Shannon, M.C., C.M. Grieve, and L.E. Francois. 1994. Whole-plant response to salinity, p. 199-244. In: R.E. Wilkinson (ed.). Plantenvironment interactions. Marcel Dekker, New York.

Suarez, D. L. and J. Simunek. 1997. UNSATCHEM: Unsaturated water and solute transport model with equilibrium and kinetic chemistry. Soil Sci. Soc. Amer. J. 61:1633-1646.

Tanji, K., S. Ford, A. Toto, J. Summers, and L. Willardson. 1993. Evaporation ponds: What are they; why some concerns, p. 573-594. In: R.G. Allen and C.M.U. Neale (eds.). Management of irrigation and drainage systems: Integrated perspectives. Proc. 1993 Natl. Conf. Irrig. Drainage. Amer. Soc. Civil Eng., New York.

van Genuchten, M. Th. and G.J. Hoffman. 1984. Management aspect for crop production: Analysis of crop salt tolerance data, p. 258-271. In: I. Shainberg and J. Shalhevet. (eds.). Soil salinity under irrigation, processes and management. Ecological Studies 51. Springer Verlag, New York. 